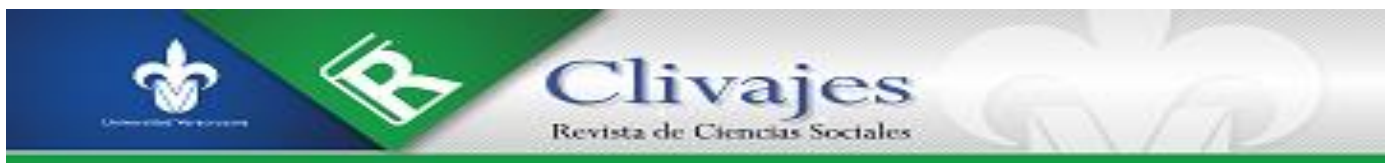

Isaac Enríquez Pérez

LOS LABERINTOS DE LA GLOBALIZACIÓN Y SUS MANIFESTACIONES EN LA DIALÉCTICA DESARROLLO/SUBDESARROLLO: VARIACIONES Y NOTAS CRÍTICAS

Clivajes. Revista de Ciencias Sociales. Año V, número 10, julio diciembre 2018, pp. 66-94. http://clivajes.uv.mx/index.php/Clivajes/article/view/2547/4434 Instituto de Investigaciones Histórico-Sociales, Universidad Veracruzana

C livajes. Revista de Ciencias Sociales/ISSN: 2395-9495/IIH-S, UV/Xalapa, Veracruz, México.

Recibido: 17-01-2018

Aceptado: $15 / 02 / 2018$

Dictaminado: 19/06/2018

Publicación: 03/12/2018

Clivajes. Revista de Ciencias Sociales (ISSN: 2395-9495), Año V, Núm. 10, julio-diciembre, 2018 


\title{
LOS LABERINTOS DE LA GLOBALIZACIÓN Y SUS MANIFESTACIONES EN LA DIALÉCTICA DESARROLLO/SUBDESARROLLO: VARIACIONES Y NOTAS CRÍTICAS
}

\author{
Isaac Enríquez Pérez ${ }^{*}$
}

\section{Resumen}

Más allá de la tergiversación, redundancia, confusión y dispersión conceptual, este artículo significa un esfuerzo interdisciplinario por vertebrar una noción de "globalización", a partir de sus manifestaciones y su raigambre inédita y contemporánea, al tiempo que incursiona en el debate sobre su incidencia en tópicos como la dialéctica desarrollo/subdesarrollo, las transformaciones de la soberanía nacional, las funciones que adopta el aparato de Estado, el proceso de planeación y el diseño y ejercicio de las políticas públicas. Se interpreta la globalización como un proceso multidimensional que trasciende el espacio económico para situarse como reconfiguración del tiempo y el espacio, y perfilarse como una tendencia a la transcontinentalización de las relaciones sociales y la compresión del mundo como un todo único, diferenciado y diverso, y que tiene a las redes como su principal infraestructura organizacional, la cual modifica, entre otras cosas, el proceso de toma de decisiones y la nueva naturaleza del espacio público al interior de las naciones, a la vez que se estructuran espacios globales para la toma de decisiones. ${ }^{1}$

Palabras clave:

Globalización, Dialéctica desarrollo/subdesarrollo, Políticas públicas, Espacios globales, Soberanía, Dislocamiento del Estado

\section{INTRODUCCIÓN}

Desde 1989, a medida que los fundamentos de la economía mundial y la política internacional tendieron a redefinirse y radicalizarse, y conforme la misma transcontinentalización de las relaciones sociales se profundizó y expandió por distintas latitudes, a lo largo y ancho del planeta tierra, se gestó la globalización como tendencia sociohistórica inédita y, con ello, se volvió la mirada hacia la gravitación que ejercen las interacciones e interconexiones transplanetarias y supra-territoriales en el proceso de toma de decisiones relativas al diseño y ejercicio de las políticas públicas. La noción de que la sociedad nacional trasmuta en una sociedad global entretejida, integrada, interconectada e interdependiente que gravita en torno a, e irradia efectos en, fenómenos y procesos suscitados en los territorios locales, se vertebra, a

\footnotetext{
* Doctor en Economía del Desarrollo, maestro en Historia del Pensamiento Económico y licenciado en Sociología. Académico en la UNAM, es miembro del SIN e Investigador Junior por CLACSO; autor de Las estrategias de desarrollo y los avatares de la planeación nacional: un estudio sociohistórico para la reconstrucción de un paradigma perdido en las políticas públicas mexicanas, libro editado por Dictus Publishing.

${ }^{1}$ Este trabajo fue realizado como parte de las actividades de investigación en la Unidad Académica en Estudios del Desarrollo de la Universidad Autónoma de Zacatecas, y financiado por el Consejo Nacional de Ciencia y Tecnología (CONACYT) a través de su Programa de Estancias Posdoctorales Vinculadas al Fortalecimiento de la Calidad del Posgrado Nacional.
} 
finales del siglo XX, como metáfora para referir una realidad inédita que trastoca el imaginario social y las formas de representar la realidad, mediante las estructuras cognitivas, de tal suerte que la intensificación de los procesos de globalización, desde la década de los noventa, generó un vendaval y un maremágnum que sembró el desconcierto y el desencanto ante la reconfiguración de la vida social tradicionalmente anclada a la sociedad nacional.

Argumentado lo anterior, cabe esbozar algunas preguntas que le dieron forma a la investigación que respalda el presente documento; a saber: ¿Qué es la globalización? ¿Cuáles son las dimensiones, manifestaciones y aristas que le dan forma a este proceso histórico? ¿De qué manera gravita la intensificación de los procesos de globalización en la dialéctica desarrollo/subdesarrollo? ¿Cómo se configuran los espacios globales para la toma de decisiones y de qué forma inciden en el diseño y ejercicio de las políticas públicas? ¿Cómo son trastocados y redefinidos la soberanía, el Estado y sus funciones esenciales de cara a las interacciones transplanetarias y supra-territoriales de las últimas dos décadas y media?

Planteados esos interrogantes, es necesario matizar que el objetivo central de nuestra investigación consistió en desentrañar y comprender el sentido del proceso de globalización, en tanto una de las tendencias que trastocan el comportamiento de las sociedades contemporáneas y modelan o moldean la lógica de la dialéctica desarrollo/subdesarrollo, al grado de reconfigurar el proceso de planeación, las decisiones públicas y la misma definición o construcción de los problemas públicos. Esto es, se pretendió interpretar y explicar que la globalización, más que un proceso estrictamente económico, es -en esencia- multifacético y precisa, para su abordaje, de cierta claridad conceptual para no confundirlo con otros fenómenos que se toman como sinónimos y que al redundar en ellos no se logra más que una desfiguración y dispersión del análisis de la realidad contemporánea.

A lo largo de la investigación, una premisa crucial fue la siguiente: la globalización es una voz que, desde la década de los noventa, se usa de manera indiscriminada hasta desdibujar su concepto y tornarlo una muletilla que bien puede apoyar discursos retóricos, apologistas o contestatarios, sin reparar en el sentido y naturaleza del proceso, ni mucho menos en las inéditas rupturas históricas y epistemológicas que representa, y-más aún- sin enfatizar en la lógica de las transformaciones del Estado y de la dialéctica desarrollo/subdesarrollo suscitadas tras su gravitación en los espacios locales/nacionales.

\section{¿QUÉ ES LA GLOBALIZACIÓN?}

DIGRESIONES EN TORNO A UN CONCEPTO NEBULOSO Y POLISÉMICO

Durante las últimas tres décadas, conforme se expandieron y profundizaron las relaciones internacionales y los fenómenos transcontinentales, tendieron a intensificarse los procesos de globalización y, con ello, a revitalizarse la incidencia de los factores externos en los procesos de 
planeación y de toma decisiones en materia de agenda pública. Comprender los alcances e impactos de la globalización en el diseño y ejercicio de las políticas públicas amerita hacer una digresión para reflexionar en torno a este proceso o tendencia.

Desde mediados de la década de los noventa, las ciencias sociales - especialmente las teorías de la globalización $-^{2}$ orientan sus esfuerzos teóricos a comprender - a partir de distintas perspectivas y sistemas conceptuales (marxismo, neomarxismo y teoría social crítica, neofuncionalismo, filosofías postmodernas, teoría de los sistemas sociales, teorías del sistema mundial moderno y de la economía-mundo capitalista; liberalismo, teoría económica neoclásica, teorías del capitalismo informacional, teoría de la estructuración, estudios culturales, sociología urbana, etc.)- una nueva e inédita realidad que impacta distintos ámbitos de las sociedades humanas y muestra variadas dimensiones y facetas.

Haciendo eco de estas contribuciones teóricas, trataremos de esbozar una noción de la voz "globalización", en aras de contrarrestar la dispersión y las imprecisiones conceptuales que le rodean y que terminan por desdibujar el concepto y vaciarlo de contenido y capacidad heurística. La globalización - a contracorriente de lo que ciertas perspectivas teóricas sostienen- no es sinónimo de imperialismo, neoimperialismo ni de neoliberalismo (término inapropiado incluso para referirse a las políticas económicas de las últimas tres décadas, que son - en esencia- neoconservadoras), colonialismo, universalización, occidentalización, internacionalización o regionalización, lo cual en sí mismo resulta redundante y confuso, aunque esas nociones remiten a procesos que se traslapan e interactúan recíprocamente en el mundo contemporáneo.

Más bien, la globalización es un proceso histórico inédito -si bien interactúa, incide y se inscribe en otros procesos históricos de larga duración, como la economía-mundo capitalista y la formación y expansión del sistema mundial moderno (Braudel, 1985; Wallerstein, 1998, 1999ª y 1999b) - relacionado con la transcontinentalización de las relaciones sociales, la formación de redes y la estructuración y compresión del mundo como un todo sistémico y diferenciado en dimensiones relacionadas con: la expansión e integración mundial del capitalismo y la formación de redes empresariales globales; la fragmentación y dispersión territorial del proceso de producción y la movilidad de las inversiones, mercancías, insumos, capitales, conocimientos y tecnologías, a partir de las alianzas estratégicas de las empresas para la fabricación y comercialización de productos globales y la estandarización de patrones de consumo; el dinamismo de las transacciones comerciales y financieras; los masivos flujos de información, comunicación y símbolos, a raíz de la emergencia de un sistema de telecomunicaciones, mundialmente integrado, que despliega conexiones

\footnotetext{
${ }^{2}$ Véanse, por ejemplo, Anthony Giddens (1990 y 2000); Arjun Appadurai (1990); Roland Robertson (1992); Malcom Waters (1995); Martin Albrow (1996); David Held (1995); David Held, Anthony McGrew, David Goldblatt y Jonathan Perraton (1999); Held y McGrew (2002); Samir Amin (1998); Ulrich Beck (1998b y 2002); James H. Mittelman (2000); Jan Aart Scholte (1996 y 2005); Saskia Sassen (2003, 2004 y 2007); Zigmunt Bauman (1999); Manuel Castells (2002, 2003, 2001 y 2006); Dirk Messner (1997); Leslie Sklair (2002 y 2003); Octavio Ianni (1996, 1998 y 1999); entre otros.
} 
instantáneas y simultáneas; la toma de decisiones transnacionales o supranacionales en materia de política económica; la formación de espacios globales para la toma de decisiones orientados a la coordinación, armonización, estandarización y homogeneización de directrices de política pública; la organización mundial de los movimientos sociales que reivindican y demandan el respeto de los derechos humanos, el disfrute del derecho al desarrollo y la reivindicación del derecho al respeto y la preservación de las culturas locales; las relaciones sociales que se desvinculan de sus espacios físicos; las redes como nueva modalidad de configuración de las organizaciones; la diversidad cultural y la convivencia ínter y multicultural; y la inserción de las sociedades - por necesidad, inercia, temor o decisión propia- en los fenómenos militares, geopolíticos, geoeconómicos y geoestratégicos.

En principio, al ser un proceso de re-espacialización y re-territorialización de la vida social, la globalización redefine las categorías de espacio y tiempo hasta comprimir al mundo como un todo articulado y, a la vez, diferenciado. Los transportes multimodales y las tecnologías de la información y la comunicación suscitan una "convergencia espacio-tiempo" (Janelle, 1969) que disminuye las distancias, con respecto al tiempo invertido en su recorrido, contrae el espacio y acerca los lugares hasta el punto de reducir la relevancia de los límites que impone esta distancia en el despliegue de la interacción social. Más aún, con el "distanciamiento o la separación tiempo-espacio" (Giddens, 1990), se gesta un desanclaje de los sistemas sociales y el ejercicio de interacciones sociales, distanciadas o remotas, en las cuales no es indispensable la co-presencia o la relación cara a cara, de tal suerte que lo local, lo nacional y lo global se traslapan para otorgarle nuevas formas al territorio y a las sociedades. Con la conjunción de estos dos fenómenos, las sociedades contemporáneas experimentan una "compresión espacio-tiempo" (Harvey, 1989) que modifica las formas de representar el mundo a partir de la aceleración del tiempo y el relativo desvanecimiento de las barreras espaciales.

Por si fuera poco, si las redes transplanetarias y supra-territoriales son la infraestructura organizacional de la globalización, tenemos que en el mundo contemporáneo prácticamente todas las praxis humanas -incluso la misma configuración de las relaciones de poder- se estructuran en red, a partir de sus múltiples nodos que facilitan, en una lógica sistémica, los flujos transcontinentales interregionales de intercambios e interacciones sociales: existen y se expanden redes empresariales en forma de telaraña para responder a la segmentación territorial de la cadena de valor y a los sistemas internacionales de producción integrada, los encadenamientos mercantiles mundiales y las redes financieras globales; redes de estados y de organismos internacionales para homogeneizar y estandarizar políticas públicas y enfrentar problemáticas comunes; redes de organizaciones no gubernamentales internacionales y asociaciones filantrópicas que se articulan para promover el derecho al desarrollo (Amnesty International, Greenpeace, Oxfam y su red de asociaciones locales, Ford Foundation); redes de movimientos sociales que, en una especie de 
globalización desde abajo, reivindican demandas propias de algún grupo o grupos étnicos y pluriculturales (Consejo Mundial de Pueblos Indígenas, Consejo Internacional de Tratados Indios, Coordinadora de las Organizaciones Indígenas de la Cuenca Amazónica, las organizaciones zapatistas, entre otros), religiosos (World Fellowship of Buddhists), ambientalistas, pro equidad de género, sin tierra, sin techo, okupa, altermundistas (pensemos en el Movimiento por la Resistencia Global, Peoples's Global Action y su Día de Acción Global, la Asociación por la Tasación de las Transacciones financieras y por la Acción Ciudadana/ATTAC, Occupy Wall Street, el Foro Social Europeo, el Foro Social Mundial y su capacidad de convocatoria), entre otros; o redes transnacionales de crimen organizado que lo mismo trafican con narcóticos o estupefacientes, con armas, órganos, personas y migrantes, que incursionan en la falsificación y lavado de dinero, combustibles robados, etcétera. Estas redes precisan de vastas dosis de conocimiento e información para articularse y funcionar de manera simultánea, instantánea, en tiempo real y a escala planetaria.

Concebida así, la globalización consiste en densas, intensas y frecuentes interacciones transplanetarias y supra-territoriales, dotadas y regidas por relaciones e interconexiones virtualmente instantáneas, que no reconocen fronteras geográfico/territoriales ni temporales, pero que pueden incentivar y propiciar el surgimiento, reafirmación y diferenciación de identidades y lealtades tanto locales como regionales; fenómenos éstos que cuando llegan a manifestarse de manera exacerbada y con perfiles separatistas y fundamentalistas en las etnias y las religiones, como consecuencia de la desigualdad y la exclusión social y económica segregadas por el sistema hegemónico, conducen a una fragmentación y socavamiento de las sociedades nacionales, una desintegración y debilidad de las instituciones, una difusión de la incertidumbre y la contingencia, y a una erosión del capital social y la organización comunitaria y autogestiva. A decir de Giddens (1990), la globalización es un proceso que se relaciona con la interacción entre presencia y ausencia; con fenómenos sociales que ocurren en cierto espacio local e impactan en sociedades localizadas a miles de kilómetros de distancia, de tal modo - argumenta Castells (2002)- que se presenta una oposición bipolar entre la red y el yo, entre la globalización y la identidad.

Una descripción visual, desde el cine, de esta relación entre presencia y ausencia se esboza en la película Babel, dirigida por Alejandro González Iñárritu en el año 2006: un hecho inicial como el regalo de un rifle de cacería, por parte de un turista japonés, en una aldea marroquí detona varios acontecimientos que marcan la vida de los personajes. Este rifle es tomado por los hijos del guía de caza y, en su uso irresponsable, disparan a un autobús de turistas estadounidenses, entre los cuales sobresale un joven matrimonio con problemas de pareja y cuyos hijos están en el estado de California bajo los cuidados de una mujer migrante indocumentada, de origen mexicano, que los traslada a la multicultural ciudad de Tijuana (México) para acudir a una tradicional boda de un hijo que no visita en años. Varias facetas culturales, cosmovisiones y lenguas se entrecruzan a través de ese hecho inicial detonado por el rifle obsequiado al aldeano marroquí. Por un lado, la vida del 
ciudadano japonés y su hija sordomuda, la distancia entre ambos ante la extraña muerte de la esposa y madre respectivamente; las dificultades de la pareja estadounidense tras la herida de la esposa en pleno desierto africano; los hijos de este matrimonio que, al intentar regresar a territorio estadounidense, es catalogado como sospechoso de secuestro o rapto de menores, por lo que procede a la fuga por el desierto del sur de la Unión Americana, y - por otro- las vicisitudes de los jóvenes que accionaron el rifle. Se trata de relaciones sociales entrelazadas, que se despliegan sin la presencia y la tradicional interacción cara a cara de los principales actores, pero cuyas acciones irradian -territorialmente y en distintos contextos sociales y culturales- efectos indeseados que escapan a sus motivaciones, decisiones e intenciones iniciales.

Varios fenómenos evidencian la emergencia e intensificación de los procesos de globalización contemporáneos: en cuanto al proceso económico, la dispersión territorial de la cadena de valor, a lo largo y ancho del mundo - de tal modo que los productos son combinaciones de insumos internacionales diseñados y fabricados en múltiples territorios-; la diseminación y coordinación territorial de unidades productivas que operan de manera simultánea para conformar redes empresariales globales; una renovada división internacional del trabajo, apoyada por el sistema de manufactura flexible, las alianzas estratégicas y las tecnologías de la información y la comunicación, en la cual las naciones desarrolladas se especializan, a grandes rasgos, en el trabajo relacionado con el conocimiento ejercido por el analista simbólico, en tanto que los países subdesarrollados se orientan - de manera interconectada con la anterior modalidad y bajo la premisa de la minimización de los costes de producción- a los trabajos de rutina o al hacer y mover cosas (Reich, 1993; Drucker, 1994 y 1996).

Un sustancioso ejemplo de los mercados de trabajo interconectados, en el contexto de esta nueva división internacional del trabajo, se muestra en la película Sllumdog Millonaire, dirigida en 2008 por el cineasta británico Danny Boyle. En cierto episodio, el filme retrata un centro de llamadas ubicado en Bombay (India) que brinda - en idioma inglés-servicios de atención en materia de telefonía móvil a clientes radicados en el Reino Unido, o bien -aunque no expuesto en esta cinta-, la señorita colombiana, sentada en la comodidad de su casa en Ohio (EUA), frente a un tablero para dar indicaciones, en distintas lenguas, sobre la documentación de equipajes, a través de los altavoces del Aeropuerto Internacional de Schiphol (Ámsterdam, Holanda), transitado por viajeros que regresan a sus hogares en Shanghái, Dubái, Johannesburgo, Ciudad de Panamá, París, Quebec, Tokio, Ciudad de México o Nueva York. Se trata de una globalización de la división del trabajo y de los mercados laborales, a partir de la flexibilización, la reducción de los costes de producción y de materias primas, y la remoción de regulaciones y de los controles fiscales del Estado.

La llamada "fábrica global” (Grunwald \& Flamm, 1985) se articula en redes de producción basadas en el despliegue de los sistemas de la manufactura flexible, que producen bienes y servicios 
en distintas y dispersas localizaciones territoriales, apoyados en alianzas estratégicas. El comercio intra-firma y el comercio internacional son fundamentales para llevar a buen puerto el ensamblado, sofisticadamente coordinado, de los productos finales. Toda la cadena de valor de un automóvil, un ordenador, un electrodoméstico, una aeronave, algún artículo deportivo o cualquier vestimenta textil se fragmenta y se integra, de manera simultánea, a partir de la coordinación -impulsada por los analistas simbólicos - en forma de telaraña de las universidades o el centro de investigación y desarrollo privado; las oficinas de diseño industrial; la intermediación y negociación con proveedores de insumos o materias primas; los talleres familiares y maquiladoras orientadas a la producción en serie de altos volúmenes a través de su cadena de montaje; los encargados de los procesos de calidad; los despachos jurídicos y contables; las unidades de procesamiento de información y datos; las agencias publicitarias; y los distribuidores finales.

Si la producción se organiza de manera simultánea en redes empresariales globales, dispersas y coordinadas territorialmente, el consumo, como fase del proceso económico, también se manifiesta de manera global. Apoyada en las industrias culturales globales, en sus estrategias publicitarias y de mercadotecnia; en las monedas transplanetarias (el dólar estadounidense, la libra esterlina, el euro, el yen, el yuan o renminbi) y el dinero plástico o electrónico - que son parte de las transacciones de divisas que operan las 24 horas del día en las redes financieras globales y en las oficinas para el envío de remesas migrantes de un extremo a otro del mundo-; en la masificación del crédito y en la obsolescencia tecnológica programada, la fase de consumo coloca simultáneamente los mismos bienes y servicios de alguna marca registrada y con certificación ISO entre territorios y poblaciones dispersos, penetrando en diferentes culturas. De tal modo - a decir de algunos estudiosos--, el capitalismo contemporáneo se torna global y las mercancías (en sus fases de producción y consumo) trasmutan en signos y símbolos sobreabundantes, y éstos en mercaderías que dinamizan el proceso económico, comenzando con la fase de producción y la relevancia que adquiere el conocimiento y la información - así como el acceso a sus flujos- en medio de relaciones sociales marcadas por la subjetividad de los agentes económicos y la acumulación reflexiva, y por un vaciamiento del sentido y del contenido - material y simbólico- de sujetos y objetos, del tiempo y el espacio (Lash y Urry, 1998).

Simbólica y culturalmente, la globalización se expresa en la emergencia de la inter y multiculturalidad gestada con las migraciones masivas del Sur al Norte y del Este al Oeste del mundo, las cuales tienden a conformar diásporas que reproducen la cultura y pautas de comportamiento de sus países de origen en entornos diferentes y distantes, construyéndose -al interactuar con otras comunidades- nuevas identidades y patrones culturales, tanto en la sociedades de origen como en las de destino. Interacciones y entrecruzamientos de variadas cosmovisiones, religiones, gastronomías, sonidos, gustos, sabores, olores, comportamientos, rituales, idiosincrasias y simbolismos, son los que caracterizan al mosaico cultural que le da forma a la globalización en 
ciudades como Londres, Nueva York, Tokio, Chicago, Miami, Ámsterdam, París, Los Ángeles, entre otras. De tal manera, la globalización, más que suponer una homogeneización, se rige por una diversidad cultural multidireccional, que descansa en la diferencia, la alteridad y la transformación constante de las identidades.

En diversos sentidos geográficos y culturales, esta multidireccionalidad se observa con la llamada world music (Miller \& Shahriari, 2012), que difunde los sonidos, ritmos y símbolos del sur del mundo (música folklórica, aborigen, caribeña, griega, árabe, china, hindú, africana, asiática, latinoamericana) en las radiodifusoras y salas de concierto del norte y del mundo entero, impulsada por las diásporas que trasladan su cultura, la reducción de los costes de transporte y el acceso a los medios masivos de difusión. Los sonidos tradicionales de las aldeas, producidos por las etnias locales, se combinan con géneros electrónicos y sintetizadores, y se difunden a lo largo y ancho del planeta, amalgamándose con otras culturas que los aceptan y disfrutan.

Los medios masivos de difusión tienden a magnificar estos crecientes intercambios de símbolos, así como la intensificación de las relaciones sociales a escala planetaria; ello apoyado en una red global de información y comunicación cuyo puntal tecnológico es el satélite (situación vislumbrada por Marshall McLuhan y Powers, 1989) y la Internet, como medio de comunicación supra-territorial que irradia sus contenidos en tiempo real entre las carreteras del llamado ciberespacio. A través de los mass media es posible la interconexión, la creación e irradiación de imaginarios sociales y simbolismos; la configuración de relaciones sociales y la expresión y sincronización de emociones en territorios y poblaciones distantes del epicentro en que se originan.

Una Copa Mundial de la FIFA, los Juegos Olímpicos, la UEFA Champions League - con sus correspondientes redes globales de aficionados a algún club-; la transmisión en vivo de "catástrofes naturales" y sus efectos; la muerte de un líder mundial; la difusión de los libros y películas de El Señor de los Anillos, Harry Potter, Titanic o Avatar; la gira mundial, el lanzamiento de un disco o alguna declaración polémica de Rihanna, Madonna, Lady Gaga, Beyoncé, Ariana Grande, Katy Perry, Justin Bieber o Maluma; la promoción de un producto, como el iPad o el iPhone; un evento macroliminal, como el derribo de las Torres Gemelas de New York, y los flujos masivos de información, son eventos que convocan - simultánea e instantáneamente- a grandes audiencias y logran la convergencia de sentimientos, emociones, opiniones e intersubjetividades, que traspasan territorios o fronteras y tensan la relación entre presencia y ausencia.

Esta abigarrada irradiación de símbolos e información es multidireccional y su asimilación es diferenciada en las comunidades receptoras o en las que se incorporan en sociedades y culturas ajenas, introduciendo variados elementos a los propios productos de las industrias culturales globales. Esa asimilación diferenciada, en el contexto de la globalización, es denominada por los antropólogos de la cultura como “indigeneización” (Appadurai, 1990). 
Las innovaciones en materia de tecnologías de la información y comunicación también son el sustento de la conformación de las redes financieras globales que funcionan en tiempo real, las 24 horas del día y a escala planetaria, sobre la base de transacciones virtuales y especulativas que no dependen, al menos directamente, del proceso económico material. Ello conforma una contradictoria globalización con profundas consecuencias en la vida de las sociedades nacionales, la cultura y en la soberanía económica (Castells, 2002 y 2006).

En la esfera de la praxis política, la globalización no supone - tal como lo vaticinan muchos apologetas- "el fin del Estado-nación", sino una redefinición de su perfil y funciones, e incluso un fortalecimiento de varias de sus expresiones y atribuciones. Implica también una mayor porosidad de las fronteras - más que la desaparición de éstas- ante los masivos flujos comerciales, simbólicos, informacionales, culturales, de riesgos y violencia criminal o terrorista - con su consecuente pánico planetario-; de enfermedades contagiosas (VIH/SIDA, Ébola, Síndrome Respiratorio Agudo Severo (SARS), Influenza AH1N1, "Zika”, "mal de las vacas locas” o Encefalopatía Espongiforme Bovina), contaminantes, sonidos, imágenes, ideas, textos, y de personas -incluso migrantes indocumentados y sexoservidoras-, así como el debilitamiento y la refuncionalización de la soberanía nacional, más no su desmantelamiento, pues, pese a que los estados ceden porciones importantes de ella para la configuración de regímenes internacionales, mantienen decisiones y facetas estratégicas bajo su tutela, incluso ante la configuración y expansión de espacios globales para la toma de decisiones.

La misma irradiación global del riesgo (Beck, 1998a y 2002; Giddens, 1990 y 2000) impone variados desafíos a la gestión de la vida política, la toma de decisiones públicas y la soberanía nacional; en gran medida, porque múltiples fenómenos, problemáticas y amenazas -como la crisis de las instituciones emanadas de la modernidad europea, las crisis económico/financieras, el calentamiento global, el cambio climático y la crisis ecológica global; las "catástrofes naturales" (sismos, tsunamis, huracanes, inundaciones) y la expansión transnacional del crimen organizado, entre otros- desbordan las fronteras nacionales y las jurisdicciones administrativas tradicionales, $\mathrm{y}$ ameritan esfuerzos de cooperación internacional, más allá de los alcances de un Estado, con la finalidad de gestionar los llamados "bienes públicos globales” (Kaul, Grunberg, Stern, et. al., 1999). Las decisiones tomadas por los agentes, sean individuales o a la escala de empresas o gobiernos, generan efectos y consecuencias, concatenados y entrelazados globalmente, al extremo de incidir en la transformación de todos los espacios y habitantes del orbe, configurándose así una sociedad del riesgo global (Beck, 2002).

La misma dimensión ambiental de la existencia social es trastocada por la mano del hombre, creando transformaciones ecológicas antropogénicas cuyas manifestaciones, causalidades, consecuencias y riesgos no se ciñen a las fronteras territoriales tradicionales. El agujero en la capa de ozono por obra de los clorofluorocarbonos; la pérdida de biomasa, biodiversidad y bosques; la 
diseminación de la llamada lluvia ácida; la deforestación y desertificación; la basura radiactiva; la contaminación de los mares; el estrés hídrico y la escasez de agua apta para consumo humano, son todos ellos problemas públicos diseminados con mayor velocidad e intensidad y sin límites por los mismos flujos transplanetarios.

Esta incidencia de los procesos de globalización en las escalas nacionales supone también la emergencia de la relevancia inédita que adquieren los espacios y territorios locales ante la reconfiguración de su naturaleza. Más allá del proclamado fin de la geografía (O’Brien, 1992), en los espacios locales, los procesos de globalización logran estructurarse, concretarse, materializarse y afianzarse en una relación dialéctica y de condicionamiento mutuo, puesto que en dichos espacios se gestan las condiciones - como la dotación de infraestructura física, decisiones públicas que apuntalan el proceso económico, la formación de recursos humanos, exenciones fiscales, etc.-, las ventajas competitivas y comparativas, y las oportunidades para ocupar mercados y para que las empresas rivalicen en aras de escalar posiciones en los contornos de los sistemas internacionales de producción integrada y de los encadenamientos mercantiles mundiales.

Los espacios locales se estructuran como una alternativa para contener los efectos sociales y ambientales negativos, derivados de la globalización de los mercados; además de que fundamentan la creación y reproducción de innovaciones institucionales, organizacionales y tecnológicas que desencadenan economías de aglomeración y eslabonamientos de cadenas productivas, al tiempo que se revalorizan las dimensiones simbólico/culturales de las comunidades con miras a construir capital social, organización comunitaria autogestiva y entramados institucionales orientados al diseño y ejercicio de proyectos alternativos de desarrollo endógeno. En estos espacios locales, las ventajas comparativas y su posición en el mercado se fortalecen con la convergencia de factores tanto endógenos como exógenos; y ambas, conjuntamente con la productividad, conforman elementos esenciales para la inserción ventajosa -o desventajosa, en caso de no poseerlos- de los territorios y las poblaciones en los mercados globales (sobre la relevancia de los espacios locales, véase Torres Torres, Delgadillo Macías, Gasca Zamora y Enríquez Pérez, 2009; Enríquez Pérez, 2011).

Reconociendo estas interacciones, algunos autores argumentan que los fenómenos locales y los procesos globales no se excluyen mutuamente, y que más bien lo local es una dimensión de lo global y viceversa; ello en condiciones de una relación interdependiente y en el contexto de un movimiento vinculado con la compresión del mundo como resultado de la frecuencia e intensidad de la interacción social (Robertson, 1992). En suma, lo local y lo global no son contrapuestos, sino que interactúan estrechamente y se traslapan para crear un mundo fenoménico con contornos indefinidos, de tal suerte que lo local entreteje lo global y -simultáneamente- lo global está contenido y expresado en lo local. Se trata, pues, de una naturaleza dialéctica del territorio y de las relaciones sociales. 
A grandes rasgos, lo inédito del proceso de globalización radica en evidenciar que los seres humanos -independientemente de su lugar y ubicación en el planeta- muestran una mayor propensión a interactuar e interconectarse entre sí con amplia facilidad y con mínimas restricciones en sus relaciones cara a cara, y en sus dimensiones emocional, virtual, simbólica/cultural, lingüística, material, científica/tecnológica, jurídica, política, etc., transformando con ello la lógica y el sentido del espacio social, pues la acción social y la interconectividad de las personas trascienden al Estado-nación y al territorio inmediato, y se desanclan de él hasta conformar una supraterritorialidad que se sustenta en relaciones sociales simultáneas, instantáneas y virtuales. De ahí que la globalización consista en un proceso o en una serie de procesos - en una tendencia- de reespacialización y re-territorialización de la cuestión social y de creciente, veloz e intensa interconectividad y formación de redes en el conjunto de la praxis humana, las relaciones sociales y las identidades locales/nacionales, que entran en tensión con lo transplanetario y lo supraterritorial.

Cabe destacar que no toda la población mundial ni todos los territorios están interconectados, ni quienes lo están interactúan con la misma intensidad y dosis de poder, pues la inserción de los individuos y sociedades en la globalización - pese a su omnipresencia- está en función de la estratificación social, la clase social, el género, la raza, la orientación sexual y la posición y coordenadas territoriales, generando - en contextos de incertidumbre y contingenciamárgenes y marginales signados por el conflicto, las asimetrías y la desigualdad territorial y social. El mismo procesamiento de signos y símbolos profusos - fuentes y pilares de las redes que se tejen transplanetariamente- tiende a ser asimétrico y segmentado entre sociedades y territorios, aumentando con ello la exposición a la incertidumbre.

LA DiALÉCTICA DESARROLLO/SUBDESARROLlO ANTE LA INTENSIFICACIÓN DE LOS PROCESOS DE GLOBALIZACIÓN

La globalización no es una tendencia tersa ni mucho menos armoniosa, sino que entraña y está expuesta a contradicciones, a las asimetrías y a la desigualdad social e internacional que hunde sus raíces en la naturaleza polarizada y polarizante del capitalismo y su etnocéntrica modernidad desbocada. Como no todos los individuos, sociedades y territorios se insertan a los flujos globales, y si lo hacen, no es con la misma velocidad, alcance e intensidad, ni desde la misma posición territorial o de clase social, lo que en sí se presenta es una interconectividad transcontinental desigual, asimétrica y estratificada. Esto significa que, a pesar de que existen relaciones sociales transplanetarias cada vez más densas, a ellas no se interconectan de manera plena toda la humanidad ni todos sus territorios, aunque se susciten interacciones indirectas y tangenciales entre los territorios marginales y el epicentro de la globalización. 
No todos los individuos y sociedades se interconectan a través de la Internet y las tecnologías de la información y la comunicación; del sistema de manufactura flexible que, en esencia, es excluyente y tendiente a la precarización laboral; de las decisiones políticas tomadas en espacios globales cada vez más privatizados, o de los viajes transcontinentales que facilitan el turismo, las migraciones y la formación de diásporas en territorios ajenos a aquellos que les vio nacer y crecer. Esta interconectividad transterritorial y el acceso a los flujos globales está en función de la posición social y la localización territorial, y éstas, por antonomasia, están en función del carácter estratificado y desigual de la dialéctica desarrollo/subdesarrollo, la distribución de la riqueza, las dosis de poder, el avance tecnológico, la posesión de recursos naturales y de los entramados simbólico/culturales e institucionales que signan a las sociedades.

A su vez, la globalización -con su maremágnum de flujos multidireccionales- disemina una serie de efectos multidimensionales en la dialéctica desarrollo/subdesarrollo. Si la globalización es un proceso de re-espacialización y re-territorialización de la vida social, fundamentado en la configuración de redes transplanetarias y supra-territoriales como nueva infraestructura organizacional, y si a partir de ello son redefinidas las categorías de espacio y tiempo hasta comprimir y estructurar al mundo como un todo articulado y diferenciado, lo que se tiene es que la globalización - al intensificarse las interconexiones y relaciones sociales-irradia y transcontinentaliza una gran cantidad de fenómenos y desafíos que desbordan las fronteras convencionales, y, al resultar problemáticos para las comunidades locales, se relacionan - directa o indirectamente- con la dialéctica desarrollo/subdesarrollo.

Las “catástrofes naturales" y la devastación y crisis ambiental (el efecto invernadero o el cambio climático); las crisis económico/financieras; la reconfiguración de la división internacional del trabajo y la localización de la producción en distintos y distantes territorios coordinados; la hibridación de las culturas y los diálogos interculturales; la difusión de acontecimientos y eventos mediáticos; la formación de espacios globales y redes globales de toma de decisiones, a partir de la interacción de funcionarios públicos nacionales y de organismos internacionales, Think Tank's, comunidades epistémicas (sobre este concepto véase Haas, 1992), cabilderos de intereses privados, filántropos y líderes de organizaciones no gubernamentales internacionales; las guerras, los atentados terroristas y la violencia criminal de distinto tipo; las migraciones humanas masivas en múltiples direcciones; las enfermedades y pandemias diseminadas y portadas por los turistas, inmigrantes, refugiados, trabajadores cualificados o no cualificados; la pobreza y la desigualdad que no respetan ni Norte, ni Sur, ni Este, ni Oeste, son fenómenos que rebasan las fronteras y territorios nacionales/locales hasta tornarse desafiantes de las instituciones propias del Estado-nación y de sus instrumentos de intervención, política y gestión del desarrollo. Buena parte de las decisiones en materia de política y gestión de los 
problemas públicos se diseña y difunde, a su vez, desde espacios globales piloteados por organismos internacionales que privilegian ciertas concepciones sobre el desarrollo y no otras, reforzando los desafíos que desbordan a las instituciones nacionales.

La exposición de las sociedades y territorios nacionales y locales, ante este maremágnum de fenómenos -según sus particulares relaciones de poder, la correlación de fuerzas y la densidad y fortaleza institucional-, magnifica o atempera las contradicciones originales del capitalismo y sus relaciones sociales, asimétricas y desiguales. Si bien la globalización no gesta dichas contradicciones, sí las disemina, expansiva y simultáneamente, a lo largo y ancho del planeta, afectando a aquellos individuos y poblaciones que no se insertan de manera directa en las interconexiones transplanetarias. En ese sentido, la globalización no es una tendencia neutral, ni mucho menos homogeneizadora de las condiciones de vida y de los niveles de bienestar, como ideológicamente se difunde. De esta forma, la dialéctica desarrollo/subdesarrollo es trastocada por la globalización, conforme se suscitan fenómenos y problemáticas que no tienen su origen en las escalas locales/nacionales, y que tornan al planeta en una sola casa común a todos, y conforme se diseñan - ante ello- políticas públicas que no tienen como racionalidad última a las sociedades nacionales, ni responden únicamente a las decisiones que toman sus actores y agentes socioeconómicos y políticos.

El paisaje de la globalización muestra dos rostros entrelazados: el de la integración/articulación y el de la fragmentación/desarticulación de las sociedades nacionales. Y precisamente, estos rostros dialécticos y simultáneos inciden de manera diferencial en el ámbito mundial y en el propio de los territorios de los estados-nación, reconfigurando también sus instituciones estatales, el espacio público, el ejercicio de los derechos de la ciudadanía, y el disfrute del derecho al desarrollo y a la diferencia. Como la incertidumbre y la contingencia son signos de la globalización, todo impacto de ésta es asimétrico en el tiempo y en el espacio; desigual entre territorios y sectores; multidimensional, al afectar distintos tipos de praxis (política, económica, simbólico/cultural, jurídica, estética, científico/tecnológica); y multiescalar (afecta a la vez en el plano mundial, nacional, regional y/o local), al tiempo que sus efectos inciden desde afuera y desde adentro, desde arriba y desde abajo. En este escenario, la dialéctica desarrollo/subdesarrollo se tensa entre la afirmación del individualismo a ultranza y el eslabonamiento de identidades colectivas que -dotadas de fuerte arraigo local y, a la vez, proyección transplanetaria- reivindican los derechos ciudadanos.

En particular, se suscita la emergencia y expansión de una institucionalidad global que modela las decisiones de los espacios públicos, regulados no sólo por el Estado, sino también por organismos internacionales, agencias privadas, organizaciones no gubernamentales internacionales, y redes empresariales globales, de tal manera que, ante la agudización de las 
desigualdades sociales e internacionales, en medio de la correlación de fuerzas y las luchas por la hegemonía mundial, se estructuran - desde arriba y desde abajo- proyectos para contener sus efectos sociales negativos y tornarlos funcionales a la lógica de las relaciones de poder, la acumulación de capital y de los imaginarios sociales convencionales, que se rigen por los preceptos de las industrias culturales globales; de ahí que la dialéctica desarrollo/subdesarrollo se encauce, en el marco de la incertidumbre y en el contorno de sus proyectos hegemónicos o alternativos, por encrucijadas de discontinuidad y ruptura constante y no de linealidad histórica -como lo argumentaron las teorías de la modernización-; de senderos contradictorios y disruptivos, no armoniosos y en equilibrio -como lo creé dogmáticamente la teoría económica neoclásica-, incluso fragmentados y no plenamente integrados; multifacéticos y no monotemáticos - como lo resolvieron los planificadores económicos de antaño-, diferenciados y no homogéneos - tal como lo refuta la teoría social crítica.

Más aún, aunque tiene una raigambre nacional, la desigualdad social se manifiesta e irradia a escala global. Al erigirse un sistema mundial transterritorial, interconectado e integrado de manera asimétrica, la desigualdad no tiene límites, pues - a contrapelo de la socorrida hipótesis de Kuznets- se expande como bola de nieve, lo mismo en el Norte que en el Sur, en el Este que en el Oeste; de ahí que fenómenos sociales como la pobreza sean diseminados por la misma globalización (Chossudovsky, 2002). No menos importante en este contexto es el hecho de que en las sociedades contemporáneas prevalecen, e incluso se profundizan, las asimetrías en la toma de decisiones públicas y en materia de acceso y posesión del conocimiento y la información.

A grandes rasgos, con la intensificación de la densidad y velocidad institucional de alcance transplanetario y supra-territorial, el Estado-nación, sus instituciones tradicionales y demás mecanismos de regulación de la vida social son trastocados, reconfigurados y hasta socavados según la latitud geográfica y la fortaleza o debilidad de su vida pública. De ahí que al redefinirse el Estado, sus potestades, jurisdicciones y funciones, se redefine también la dialéctica desarrollo/subdesarrollo.

FORMACIÓN DE ESPACIOS GLOBALES Y RELACIONES ESTRATÉGICAS EN LA HECHURA Y ADOPCIÓN DE POLÍTICAS PÚBLICAS

En los espacios locales -en el contexto de una relativa desterritorialización o, mejor dicho, de una re-territorialización de las instituciones-, las políticas públicas resultan instrumentos fundamentales para la inserción, contención y convivencia dialéctica con los procesos de 
globalización - sobre todo de los relacionados con la expansión e integración planetaria de los mercados. Sin embargo, dichas políticas públicas - en el caso de regiones como América Latina y países como México- son limitadas, condicionadas y estructuradas a partir de la gravitación que ejercen los procesos de globalización y las decisiones tomadas en espacios globales de negociación interestatal. Esto es, no existe una autonomía plena en la definición de lo que deben ser los problemas públicos a atender por el gobierno -especialmente de naciones subdesarrolladas, pero no solo-, menos aún en el diseño de las políticas públicas y las posibles soluciones apropiadas para ello, en gran medida porque las ideologías y los sistemas conceptuales que pueden sustentar esos procesos están condicionados - regularmente- por el etnocentrismo y la asimilación mecánica y acrítica de concepciones ajenas a la realidad abordada.

En este sentido, cabe argumentar que la planeación del desarrollo está influida por las decisiones y acciones de actores y agentes no necesariamente pertenecientes al espacio local o nacional en cuestión, y por el despliegue de mercados que escapan al control absoluto de los estados restringidos y retraídos, que - en no pocos casos- ejercen intervenciones selectivas y débiles - e incluso nulas- en el conjunto del proceso económico y la vida social (para el caso de México, consúltese Enríquez Pérez, 2016). Además, las políticas públicas y las decisiones en torno a ellas tienden a ser más receptivas y sensibles a las transformaciones y dinamismo de las relaciones internacionales y la interdependencia transnacional, principalmente porque la economía mundial y la política internacional se erigen en renovadas racionalidades en el diseño y adopción de las políticas públicas. La misma acción de los actores y agentes gubernamentales y el perfil de la agenda pública que la inspiran están en función de acontecimientos, dinámica y decisiones en materia de política económica, los cuales se presentan en otros países y espacios locales influyentes, y capaces de posicionar sus ideologías e intereses en el debate público internacional y estandarizarlos en documentos estratégicos diseñados y difundidos por las organizaciones interestatales.

A grandes rasgos, con la intensificación de los procesos de globalización, la configuración de la agenda pública y el diseño y ejercicio de las políticas públicas nacionales se exponen a los límites y condicionamientos que imprimen las políticas y acciones gubernamentales adoptadas en otros países, y negociadas también en espacios globales para la toma de decisiones. La autonomía de las políticas públicas tiende a erosionarse con la proliferación de las relaciones estratégicas entre el mercado, el sector público y los actores socioeconómicos. Como la globalización tiene que ver con la interacción entre presencia y ausencia, o con relaciones sociales que se gestan sin que los actores se encuentren presentes físicamente en el espacio o territorio donde se manifiestan, una relación estratégica se produce con las decisiones que adopta un agente en determinado mercado, y éstas provocan efectos y consecuencias en otras latitudes y sociedades que se 
encuentran a miles de kilómetros de distancia. De ahí la relevancia de la armonización, estandarización, homogeneización, convergencia y coordinación de las políticas públicas en el plano global.

Los espacios globales para la toma de decisiones son, precisamente, la evidencia del proceso de relativa desterritorialización o de re-territorialización de las instituciones. Los agentes y su proceso de toma de decisiones públicas se desvinculan o desarraigan de los espacios geográficos tradicionales y de raigambre local/nacional, a partir de la densidad y de las redes que forman las interconexiones transplanetarias y supra-territoriales que desbordan las jurisdicciones y los alcances de las instituciones nacionales, pero que, a su vez, las tornan funcionales al erigirse en partes componentes de los nodos que estructuran dichas redes. Esto no quiere decir que desaparezcan los espacios físicos o geográficos, ni que los espacios globales se desplieguen al margen de ellos, sino que adquieren nuevas formas y se redefinen al tejer las constelaciones del poder y de la institucionalidad global.

Se trata de un nuevo ejercicio de la acción colectiva, la toma de decisiones y de regulación de la vida pública, configurado -formal o informalmente- y piloteado por agentes supranacionales (redes empresariales globales, comunidades epistémicas, Think Tank's, agencias privadas, organismos internacionales, organizaciones no gubernamentales internacionales) que condensan los esfuerzos, conocimiento, información, códigos de comunicación, contactos y alta cualificación de los expertos y analistas simbólicos, y que se despliegan en aras de construir poder y ejercer el control en los vértices y contornos de estos espacios globales que se configuran en relación orgánica con estructuras de poder e instituciones nacionales y locales. Se trata de espacios de poder virtuales y sin ubicación geográfica específica, capaces de ejercer -con su gravitación en las instituciones y el espacio público nacional-una enorme influencia en la asignación y distribución de la riqueza, el conocimiento y los recursos naturales.

En materia de diseño y adopción de políticas públicas, específicamente, las tendencias de los espacios globales, orientadas a la armonización, convergencia, estandarización, homogeneización y coordinación de estrategias, estructuras jurídicas, organizaciones e instituciones, colisionan y entran en tensión con la reivindicación de la diferenciación y reafirmación desde los espacios nacionales y locales dotados de sus respectivas necesidades, recursos, intereses, identidades culturales e idiosincrasias institucionales. Sin embargo, en última instancia, estos regímenes de regulación global se eslabonan de manera sistémica tras la convergencia y el entretejido de arenas, escenarios y espacios de poder, locales y nacionales, ubicados en los rincones cercanos y más recónditos del planeta, sin que la globalización suponga su desaparición o erosión definitiva, sino su dimensión espacial básica, desde la cual se proyecta, materializa y despliega dicha tendencia o proceso. 
El espacio público se redefine a partir de la incidencia de los espacios globales para la toma de decisiones, así como de agentes privados que hacen valer sus intereses y privilegios en la arena de las políticas públicas, de tal modo que los estados-nación no logran mostrar en sus instrumentos de planeación todo su potencial para ejercer la regulación de los flujos financieros globales, las transacciones comerciales intra e interregionales; el deterioro ambiental; las oleadas migratorias y simbólico/culturales; la propiedad y los flujos de conocimiento e información; las posibilidades de seguridad y paz internacional; la pobreza y la exclusión social; los medios electrónicos y digitales; los movimientos sociales globales, ni de toda estructura jurídica consensuada y sancionada internacionalmente. Pese a que las políticas públicas nacionales no son suficientes para la gobernanza de gran cantidad de problemas públicos que desbordan las fronteras nacionales, son indispensables para configurar, apuntalar y perfeccionar la institucionalidad global, y para trazar - desde el Estado- los contornos de la economía y la política internacional.

Como hoy en día prácticamente ningún Estado-nación queda al margen de la comunidad de naciones y de la formación de regímenes internacionales, las normas y pautas de comportamiento derivadas de los convenios, declaraciones, acuerdos y protocolos suscritos por los estados miembros extienden su obligatoriedad - desde los cauces del derecho internacionala ámbitos como el de los derechos humanos, la preservación ambiental, los derechos de propiedad y de autoría; la certificación de la calidad, y la circulación monetario/financiera y de mercancías, en una constelación de "soberanía compartida", donde múltiples agentes, como los organismos internacionales, las agencias privadas, las comunidades epistémicas, las organizaciones no gubernamentales internacionales y los movimientos sociales globales muestran una importante capacidad de teledirección y de gravitación en el diseño de políticas públicas, como parte de la intensidad, densidad y velocidad institucional que caracteriza a la globalización. Sin embargo, esta relación orgánica no es tersa, sino preñada de contradicciones, resistencias, cooperación y competencia, que alimentan la posibilidad de que las políticas públicas nacionales sean trascendidas y subsumidas por esa institucionalidad global emergente.

\section{LA SOBERANÍA ANTE EL ASEDIO DE LA GLOBALIZACIÓN Y EL DISLOCAMIENTO DEL ESTADO}

Tras considerar los mencionados procesos, resulta necesario reflexionar de manera explícita en torno a la forma en que influye la globalización en la soberanía nacional. Para empezar -y tal como se introdujo en parágrafos anteriores-, es necesario argumentar que otra de las expresiones de la globalización consiste en una redefinición y erosión -sin que ello implique su 
desaparición- de lo que tradicionalmente se denominó “soberanía nacional”. La convergencia, estandarización, armonización, homogeneización y coordinación de las políticas públicas son promovidas por los regímenes y organismos internacionales - muchas veces sin reconocer las especificidades históricas y las estructuras socioeconómicas de los espacios locales-, a través de relaciones de poder y correlación de fuerzas que desbordan a los gobiernos nacionales, pero cuyos actores y organizaciones líderes terminan por legitimarlas, al mismo tiempo, al compenetrarse y estar genuinamente convencidos de los objetivos planteados y negociados en los documentos estratégicos.

Más allá de quienes apuestan por la creación de una constitución política mundial, no menos importante en este sentido es la globalización experimentada por la praxis jurídica a través de regulaciones y normas derivadas de las convenciones suscritas por los estados ante organismos internacionales, y en rubros como la defensa de los derechos humanos, el control del armamento de destrucción masiva, los procesos de calidad y certificación, la preservación ambiental, los crímenes de lesa humanidad y demás delitos internacionales, etcétera. La soberanía nacional es trastocada en sus fundamentos esenciales al momento en que los gobiernos -mediante negociaciones, acuerdos, convenios y tratados- ceden y comparten fracciones importantes de sus decisiones, funciones, facultades, poder y autoridad respecto a los regímenes y organismos internacionales y los bloques regionales resultado de la integración económica, monetaria y política.

La soberanía - definida como el derecho a la autodeterminación de los pueblos y la propia facultad para regular y controlar los territorios y poblaciones de algún Estado-nación- tiende a desdibujarse y redefinirse con la presencia y el despliegue del poder de actores, agentes e instituciones transnacionales, supranacionales o globales que pretenden hegemonizar la regulación y gobernanza del mundo o de sus regiones. Incluso la emergencia de poderes fácticos (el crimen organizado, las organizaciones religiosas, los movimientos separatistas y fundamentalistas; el posicionamiento de monopolios transnacionales en los sectores económicos estratégicos y dinámicos) al interior de los países, tiende a apuntalar este trastocamiento de la soberanía nacional tradicional, al ser socavada desde arriba y desde abajo, desde afuera y desde adentro.

Para algunos estudiosos, lo anterior modifica profundamente el perfil del aparato de Estado en cuanto a las facultades, funciones y territorios en que concentra su actividad y autoridad, además de que pierde terreno y se retrae en materia de regulación de las distintas modalidades de flujos relacionados con las interconexiones transfronterizas (Salas-Porras, 1999). De tal suerte, el Estado pierde la potestad absoluta en la construcción de los imaginarios sociales y políticos, así como en la articulación de los proyectos de sociedad. Por si fuera poco, su capacidad reguladora tiende a socavarse ante los mecanismos emergentes de regulación y 
gobernanza global; de ahí que la soberanía se erosione ante la gravitación de una pluralidad de agentes públicos, privados, cívicos, interestatales, no gubernamentales, informales y/o criminales, con los cuales el Estado comparte sus funciones, facultades y atribuciones (Bokser y Salas-Porras, 1999; Salas-Porras, 1999). La misma incidencia en la esfera del Estado y de los organismos interestatales, por parte de movimientos sociales globales y organizaciones no gubernamentales internacionales de corte pacifista, ambientalista, feminista, pro vivienda, o pro derechos humanos, gesta una especie de espacio público global que erosiona el centralismo tradicional, coloca en la mesa de debate temáticas de la agenda pública y trata de incidir en la definición de los problemas públicos y en las estrategias de intervención; de ahí que esa pluralidad de agentes que inciden en el Estado-nación desde afuera y desde adentro, desde arriba y desde abajo, y socavan la soberanía en el maremágnum de los flujos globales, relativicen la influencia de las coordenadas espaciales y temporales en la configuración de las interconexiones, las instituciones y los agentes relacionados con el espacio público y la arena del Estado.

Así pues, no son indispensables la cercanía geográfica -las distancias se relativizan y pierden relevancia- ni el enclaustramiento en las fronteras nacionales para incidir en el perfil y funciones del Estado, así como en la redefinición de su soberanía. Es la estructura de poder para la regulación y gobernanza global la que condensa la influencia de esta pluralidad de agentes y la que, en última instancia, erosiona los alcances, autoridad y ejercicio soberano de la toma de decisiones del Estado, al tiempo que -dialécticamente- los estados-nación promocionan, negocian -no siempre en las mismas condiciones-, suscriben y legitiman los acuerdos y regímenes que le dan forma a dicha estructura de poder, contrariando todo ello el eufórico supuesto ideológico de la desaparición del Estado (Ohmae, 1990 y 1995; Fukuyama, 1992; Drucker, 1994).

El Estado no desaparece, sino que incluso -al refuncionalizarse o reconfigurarse su soberanía y el ejercicio de ésta- se expande y se torna fuerte e incisivo en múltiples esferas y se compromete fervorosamente en la promoción y legitimación de los procesos de globalización, y en la conformación de las nuevas estructuras de poder, dominación y hegemonía transplanetarias; de ahí que, con la intensificación de los procesos de globalización, la soberanía no sea más un principio supremo, exclusivo, vertebrador y omniabarcador de los estados especialmente de aquellos que se insertan de manera desventajosa en la economía mundial y la política internacional- con respecto a su población, el territorio y el ejercicio de la autoridad; la vigilancia y el control absoluto de cara a los flujos e interconexiones transcontinentales y supraterritoriales que tienden a desanclarse del tiempo, el espacio y de las fronteras tradicionales, mientras nuevos estados emergen (pensemos en la antiguas repúblicas soviéticas); otros más se fragmentan, como en el caso de la antigua Yugoslavia; en tanto que otros atraviesan por 
tendencias a la reafirmación nacional en aras de proteger sus fronteras, su aparato productivo o su identidad nacional, de cara a los flujos migratorios, comerciales y monetarios/financieros, expresando esto último el carácter reversible de la llamada desterritorialización de las instituciones.

La relación entre la institucionalidad global y las instituciones nacionales y/o locales, pese a la cooperación y al carácter interdependiente que asume, no siempre es tersa ni armoniosa, sino contradictoria y dotada de regresiones. Más aún, algunos agentes, como los organismos internacionales, los Think Tank's y las agencias privadas, trascienden y se imponen a los alcances y jurisdicciones de los estados; aunque también cabe destacar que, para los estados, la conducción política y el ejercicio de la autoridad atraviesan por su articulación en regímenes internacionales y sistemas de "soberanía compartida" que fortalecen sus funciones y configuran sus procesos de toma de decisiones (Messner, 1997).

Desde una óptica crítica, como la expuesta por Ulrich Beck (1998b), Se argumenta también, se argumenta también que, con los procesos de globalización, tanto el poder de la política nacional -que pierde su capacidad y potencial vinculante entre los ciudadanos al no lograr del todo la delimitación de los marcos jurídicos, sociales y ecológicos-como la soberanía tienden a diluirse entre la dinámica de la economía mundial y la individualización -que profundiza la porosidad de la sociedad y la pérdida de su conciencia colectiva-, y que, en general, las instituciones se debilitan.

Detrás de estas transformaciones - siguiendo al mismo Beck (1998b) y a otros autores, como Ianni (1996, 1998 y 1999)- está la noción de que en el mundo contemporáneo los seres humanos ya no (con)viven ni despliegan - de manera exclusiva, agregamos nosotros- su acción social en las sociedades nacionales ni en los espacios delimitados por los estados; de tal forma, las fronteras son trascendidas por las relaciones sociales, el proceso económico transcontinentalizado, los flujos masivos de información, las tecnologías, la crisis ambiental, las tensiones culturales, etc., todo lo cual genera una aldea global (metáfora introducida por McLuhan y Powers, 1991) que interconecta y erosiona las distancias, mediante la simultaneidad, instantaneidad y la translocalización de eventos que se sincronizan en el tiempo y se irradian en el espacio formando redes y estructurando un mundo comprimido, denso y acelerado.

Sin embargo, podemos argumentar que, a pesar de la dispersión de las decisiones estratégicas y de la erosión de la soberanía que implica su redefinición, y el compartirla con otras entidades de corte supranacional, los aparatos de Estado desempeñan un papel fundamental en la estructuración de los mercados globalizados y en la modelación de la sociedad, adquiriendo con ello una mayor complejidad en sus funciones. Más aún, variadas dimensiones de la globalización 
serían prácticamente imposibles sin la activa intervención de los aparatos de Estado y los contornos que trazan para el despliegue y regulación de aquélla.

Con la globalización, se perfilan variadas arenas de decisión en red piloteadas por múltiples agentes entrelazados, que tienen como epicentro de su poder a cuasi estados supranacionales (pensemos en la Unión Europea y otros mecanismos de integración), organismos internacionales, estados nacionales, formaciones regionales subnacionales y territorios locales, y en las cuales no sólo concurren funcionariados de gobiernos nacionales e internacionales, sino también fundaciones y agencias privadas (desde filantrópicas hasta Think Tank's y organizaciones financieras y calificadoras), organizaciones no gubernamentales internacionales, líderes de movimientos sociales globales que sin participar directamente con el Estado, le dan forma a la praxis política y al espacio público transplanetario; y otros agentes que inciden con su capital social perverso, desde el crimen organizado transnacional, los conflictos multiétnicos y organizaciones terroristas, diseminándose y erosionándose así el poder histórico del Estado y fragmentándose la soberanía nacional - especialmente en el mundo subdesarrollado.

Esto es, el imperativo de configurar una institucionalidad transplanetaria y supraterritorial con miras a proyectar, apuntalar y legitimar la expansión e integración global del capitalismo como modo de producción y proceso civilizatorio, conduce a un trastocamiento de la soberanía a partir de la formación de redes globales de toma de decisiones - en las cuales los estados, de manera diferenciada, son agentes protagónicos- que conforman su propia soberanía a través de su poder y simbolismos, y contribuyen a diversificar los escenarios de negociación, disputa, conflicto y conciliación de intereses variados y hasta contradictorios, en aras de la llamada gobernanza (governace).

Esta nueva manera de construir el poder torna acotado y fragmentado el poder tradicional del Estado y de sus mecanismos de mediación, como los partidos políticos, los sindicatos y los mismos poderes ejecutivo y legislativo. Por un lado, la privatización y desnacionalización del sector público, en prácticamente todo el mundo, debilitó el poder económico del Estado y su capacidad para ejercer su soberanía y la toma de decisiones en el proceso económico; por otro lado -aunque de manera paralela a esto último-, la transnacionalización de las decisiones políticas también vació al Estado de su carácter omnipresente y omniabarcador, limitando sus intervenciones y alcances estructuradores de la sociedad; de ahí que los espacios globales para la toma de decisiones y las redes globales de toma de decisiones - como parte de la mencionada re-territorialización y relativa desterritorialización de las instituciones- logren la convergencia -no siempre armoniosa ni lineal- de agentes con poder y de organizaciones influyentes en distintas escalas (global, internacional, nacional, local/regional o en una combinación de varias de ellas), que contribuyen a configurar 
entramados jurídico/institucionales que formalizan ámbitos de decisión y de estipulación de reglas o normas de alcance planetario.

Desde regímenes internacionales en varios rubros, tratados, convenciones, protocolos, acuerdos, declaraciones internacionales, hasta procesos de integración regional formal (por ejemplo, el Banco Central Europeo, la Comisión Europea, el Consejo Europeo y el Parlamento Europeo), pasando por procesos de integración regional menos formales, acuerdos y tratados bilaterales de distinto tipo e incluso políticas públicas de corte transnacional o binacional, configuran formas de gobernanza y de construcción del poder, en la medida en que el mundo se comprime como un todo y se perfila una especie de estructura jurídica global para atender el cauce y las contradicciones que adoptan la economía mundial y la política internacional.

\section{CONSIDERACIONES FINALES SOBRE LA INVESTIGACIÓN.}

En principio, la globalización no es un camino lineal, una tendencia irreversible, ni está dada de una vez y para siempre. Más bien, es un proceso sociohistórico contradictorio; dotado de avances y regresiones, de reconfiguraciones en la sociedad, expuestas a posturas y formas de vida endógenas, introvertidas o extrovertidas, respecto a las interconexiones más allá de sus fronteras espaciales y temporales. Como proceso inédito, por un lado, se presta a deformaciones, tergiversaciones y falta de acuerdos en torno a la definición de su concepto, lo cual -por supuesto- tiende a menguar su capacidad heurística y a eclipsar la naturaleza y dinámica de los fenómenos que pretende explicar o con los cuales se confunde; por otro lado, en tanto proceso que reconfigura las relaciones sociales de finales del siglo Xx y principios del siglo XXI, la globalización supone rupturas históricas y epistemológicas que trastocan las vivencias y las formas de imaginar y pensar el mundo contemporáneo.

En particular, estas rupturas metodológicas y epistemológicas en las ciencias sociales y en las formas de pensar e investigar la realidad social se fundan en la emergencia de procesos y fenómenos contemporáneos que trastocan los conceptos y categorías acuñados desde el siglo XVII para el estudio de la sociedad nacional, que no se corresponden con las transformaciones del finales del siglo Xx, y que apuntalan a una sociedad global emergente (un primer acercamiento a esta ruptura fue enunciada por Giddens, 1990; Ianni, 1996; Scholte, 1996 y 2005; y SalasPorras, 1999). Conceptos como Estado-nación, soberanía, legitimidad, autoridad, democracia, partido político, sindicato, entre otros, están anclados a una raigambre territorial propia de la sociedad nacional, en tanto que se tornan difusos o nebulosos en el escenario de la sociedad de redes e interconexiones transplanetarias y supra-territoriales que modifican el proceso económico, las relaciones sociales y los intercambios simbólico/culturales. 
Entre los desafíos que suscita esta ruptura epistemológica en las ciencias sociales destacan los siguientes:

a) La necesidad de comprender, explicar e interpretar la emergencia de una institucionalidad global capaz de trascender los alcances de las instituciones propias del Estado-nación, que tienden a ser socavadas por la formación y despliegue de espacios globales para la toma de decisiones, traslapados con los espacios locales y nacionales;

b) asimilar las estructuras de estos espacios globales, muchas veces intangibles, y comprender el sentido de la acción social de sus agentes hegemónicos;

c) estudiar la re-territorialización de la correlación de fuerzas y de los arreglos institucionales, culturales y políticos que subyacen a estos espacios globales, no sin descuidar la supra-territorilización de las relaciones sociales con la vigencia de su carácter propiamente territorial;

d) comprender la manera en que los espacios globales para la toma de decisiones modifican el papel y las funciones del Estado, con especial énfasis en la gravitación que ejercen en el perfil de la ciudadanía, la configuración del espacio público, el comportamiento y redefinición de los agentes públicos -distinguiéndolos de los privados que participan en la construcción del poder y las decisiones públicas-, la soberanía, y en la estructura de poder para la regulación y gobernanza global;

e) ahondar en el estudio de la relación suscitada entre la intensificación de los procesos de globalización y la dinámica de la dialéctica desarrollo/subdesarrollo;

f) desentrañar el sentido de la formación de identidades globales más allá de los sentimientos y fronteras nacionales;

g) acercarse - a través de la comparabilidad-al análisis de la estandarización, armonización, convergencia, homogeneización y coordinación de las estrategias de política pública $\mathrm{y}$, en sentido más amplio, del conjunto de procesos políticos, económicos, culturales, organizacionales, institucionales y jurídicos;

h) revisar la validez y vigencia de aquellos conceptos que acompañaron a lo largo de dos siglos a las ciencias sociales en el estudio de la sociedad nacional;

i) dotarse de los conceptos, categorías e instrumentos analíticos para medir las interconexiones transplanetarias y supra-territoriales (un excelente acercamiento a este desafío lo ofrece Martínez González-Tablas, 2003) y para representar las estrechas relaciones entre agentes, estructuras y espacios globales, regionales, nacionales y locales; 
j) sustraer los marcados rasgos ideológicos que prevalecen al remitirse a la voz globalización, así como las actitudes y posturas maniqueas que estigmatizan el análisis y el debate teórico y político;

k) evitar reincidir en el economicismo ramplón que desdibuja la noción del concepto globalización y desconoce su carácter multidimensional y polifacético, tras asumir como determinantes a las transacciones comerciales y financieras;

l) cuestionar los supuestos territorialistas y reconocer que las sociedades se exponen cada vez más a una lógica supra-territorial que desborda a los países y sus fronteras o a lo internacional como objetos de estudio, sin que ello suponga asumir la desaparición absoluta de la dimensión territorial;

m) interpretar la emergencia de identidades supranacionales de agentes, grupos y clases sociales que se desvinculan de las lealtades y sentimientos nacionales tras ejercer una acción social más allá de sus fronteras (comunidades epistémicas, clase directiva global, analistas simbólicos, líderes de movimientos sociales y ONGI); y

n) desplegar la investigación interdisciplinaria con la finalidad de dialogar entre distintos campos del conocimiento en torno a una realidad social contemporánea signada por la incertidumbre, el permanente cambio y la inestabilidad, de tal modo que sea posible - con dicho diálogo- aprehender el riesgo y las transformaciones globales, más allá de las fronteras disciplinarias convencionales, que no asimilaron la relevancia de pensar en términos de sistemas complejos.

Si la tendencia contemporánea consiste en la configuración de interconexiones y flujos transplanetarios en forma de redes, cabe destacar que éstos se encuentran arraigados en localizaciones territoriales que los eslabonan y proyectan, y desde allí se estructuran las distintas facetas y dimensiones que le dan forma a la globalización, así como a la dinámica de la dialéctica desarrollo/subdesarrollo, al perfil y funciones del Estado, y a las transformaciones de la soberanía nacional. Más aún, comprender a cabalidad el comportamiento de estos últimos, amerita - al margen del determinismo económico - desentrañar la naturaleza y el sentido de la globalización como proceso multidimensional, dotado de relaciones sistémicas y radiales que desbordan las tradicionales fronteras.

Ante ello, cabe cuestionarse lo siguiente: ¿Cómo remover y trascender los conceptos y categorías propios de la metodología del territorialismo nacionalista, que aún predominan en el oficio de la investigación social? ¿Cuáles son los mínimos e indispensables conceptos y categorías para acercarse al estudio de las relaciones sociales transcontinentales y orientar la construcción de nuevo conocimiento en las ciencias sociales? ¿Cómo amalgamar los distintos saberes 
disciplinarios que, por su cuenta, le toman el pulso a la realidad social contemporánea y a la configuración de la sociedad red? ¿De qué manera reivindicar el estudio de la dialéctica desarrollo/subdesarrollo - tradicionalmente abordada a escalas nacional e internacional-como eje central de los estudios sobre la globalización? ¿En el contexto de la globalización es posible (re)inventar el pensamiento utópico cómo luz que ilumine caminos inciertos?

Responder a tales preguntas supone un esfuerzo urgente e impostergable, de largo aliento, que trastoca las formas de desplegar y ejercer la investigación social de cara a la intensificación de los procesos de globalización y a la configuración de una sociedad global dotada de contradicciones, asimetrías y polarizaciones que socavan - en un escenario de crisis sistémica y de crisis de sentido- las relaciones sociales ancladas a un territorio nacional y a fronteras definidas, hasta diluirse en una vorágine regida por la incertidumbre, la contingencia, la volatilidad y la profundización de la crisis (des)civilizatoria.

\section{REFERENCIAS}

Albrow, M. (1996). The global age. Cambridge: Polity Press.

Amin, S. (1998). Capitalism in the age of globalization. London: Zed Books.

Appadurai, A. (1990). Disjuncture and difference in the global cultural economy. En:

Featherstone, M. (Ed.), Global Culture. Nationalism, Globalization and Modernity (pp. 295-310). London: Sage Publications and Theory, culture \& society.

Bauman, Z. [1999 (1998)]. La globalización. Consecuencias humanas. Buenos Aires: Fondo de Cultura Económica (FCE).

BECK, U. [1998a (1986)]. La sociedad del riesgo. Hacia una nueva modernidad. Barcelona: Paidós. . [1998b (1997)]. ¿Qué es la globalización? Falacias del globalismo, respuestas a la globalización. Barcelona: Paidós.

BECK, U. [2002 (1999)]. La sociedad del riesgo global. Madrid: Siglo XXI Editores.

BOKSER, J. y SAlas-Porras, A. (1999), Globalización, identidades colectivas y ciudadanía. Política y Cultura (12), otoño, pp. 25-52.

Braudel, F. [1985 (1985)]. La dinámica del capitalismo. Madrid: Alianza Editorial.

Castells, M. [2001 (1998)]. La era de la información. Economía, Sociedad y cultura (Fin del milenio), vol. III. México: Siglo Veintiuno Editores.

. [2002 (1996)]. La era de la información. Economía, Sociedad y cultura (La sociedad red), vol. I. México: Siglo Veintiuno Editores. 
- [2003 (1998)], La era de la información. Economía, Sociedad y cultura (El poder de la identidad), vol. II. México: Siglo Veintiuno Editores.

. (Ed.) [2006 (2006)], La sociedad red: una visión global, Madrid, Alianza Editorial.

Chossudovsky, M. [2002 (1997)]. Globalización de la pobreza y nuevo orden mundial. México: Siglo XXI Editores y Centro de Investigaciones Interdisciplinarias en Ciencias y Humanidades de la UNAM.

DRUCKER, P. F. [1994 (1993)]. La sociedad postcapitalista. Bogotá: Norma.

. [1996 (1994)]. Su visión sobre la administración. la Organización basada en la información, la economía, la sociedad. Bogotá: Norma.

ENRÍQUEZ PÉREZ, I. (2016), Las estrategias de desarrollo y los avatares de la planeación nacional: un estudio sociohistórico para la reconstrucción de un paradigma perdido en las políticas públicas mexicanas. Saarbrücken: Editorial Dictus.

FukuYama, F. [1992 (1992)]. El fin de la historia y el último hombre. Barcelona: Planeta.

GidDens, A. (1990). The consequences of modernity. Cambridge: Polity Press.

- [2000 (1999)]. Un mundo desbocado. Los efectos de la globalización en nuestras vidas. Madrid: Taurus.

GRUNWALd J. \& Flamm, K. (1985). Global factory: foreign assembly in international trade. Washington: Brookings Institution Press.

HaAs, P. M. (Ed.) (1992). Knowledge, power and international policy coordination. International Organization Review, 46(1), Winter.

HARVEY, D. [1998 (1989)]. La condición de la posmodernidad. Investigación sobre los orígenes del cambio cultural. Buenos Aires: Amorrortu Editores.

Held, D. (1995). Democracy and the global order: From the Modern State to Cosmopolitan Governance. Cambridge: Polity Press.

, \& McGrew, A. (2002). Globalization/anti-globalization: beyond the great divide. Cambridge: Polity Press.

, Goldblatt, D. \& Perraton, J. (1999). Global transformations: politics, economics and culture. Stanford University Press.

IANNI, O. (1996). Teorías de la Globalización. México: Siglo Veintiuno Editores, UNAM-Centro de Investigaciones Interdisciplinarias en Ciencias y Humanidades.

—_ [1998 (1995)]. La sociedad global. México: Siglo XXI Editores.

. [1999 (1996)]. La era del globalismo. México: Siglo XXI Editores.

JANELLE, D.G. (1969). Spatial reorganization: a model and concept. In: Annals of the Association of American Geographers (59), June, pp. 348-364. 
Kaul, I., GrunberG, I. \& Stern, M.A. (Ed.) (1999). Global public goods: International cooperation in the $21^{\text {st }}$ century. New York: Oxford University Press.

Lash, S. \& URry, J. [1998 (1994)]. Economías de signos y espacios. Sobre el capitalismo de la posorganización. Buenos Aires: Amorrortu Editores.

MARTíneZ GonZÁLEZ-TABlas, Á. (2003). Reflexión metodológica en torno a la globalización. Revista Economía Mundial (9), pp. 83-110.

Mcluhan, M. \& Powers, B. R. [1991 (1989)]. La aldea global. Transformaciones en la vida y los medios de comunicación mundial en el siglo XXI. Barcelona: Gedisa.

MESSNER, D. (1997). La globalización y el futuro de la política. Observaciones desde una perspectiva europea. México: Centro de Estudios de la Reforma del Estado, Fundación Friedrich Ebert Stiftung.

Miller. T. E. \& Shahriari, A. (2012). World music: a global journey. London/New York: Roudledge Ltd.

Mittelman, J. H. (2000). The globalization syndrome. Transformation and resistance. Princeton University Press.

O'BriEn, R. (1992). Global financial integration: the end of geography. London: Pinter Publisher.

OHMAE, K. (1990). The borderless world: power and strategy in the interlinked economy. New York: Harper Business.

. (1995). The end of the Nation State: the rise of regional economies. New York: Simon \& Schuster Inc.

REICH, R. B. [1993 (1991)]. El trabajo de las naciones. Hacia el capitalismo del siglo XXI. Buenos Aires: Javier Vergara, Editor.

Robertson, R. (1992). Globalization. Social theory and global culture. London: Sage Publications.

SAlas-Porras, A. (1999). La dimensión internacional en la ciencia política. En: BOKSER, J. (Coord.), Agendas de investigación y docencia en ciencia política. Memoria del Segundo Congreso Nacional de Ciencia Política (pp. 116-133). México: Colegio Nacional de Ciencias Políticas y Administración Pública, A. C., Universidad Autónoma Metropolitana, UNAM-Facultad de Ciencias Políticas y Sociales e Instituto de Investigaciones Sociales.

SASSEN, S. [2003a (1998)]. Los espectros de la globalización, Buenos Aires: FCE.

- [2003b (2003)]. Contrageografías de la globalización. Género y ciudadanía en los circuitos transfronterizos. Madrid: Editorial Traficante de Sueños.

. [2007 (2007)]. Una sociología de la globalización. Buenos Aires: Katz Editores.

Scholte, J. A. (1996). Beyond the buzzword: towards a critical theory globalization. In: Kofman, E. \& Youngs, G.. Globalization: theory and practice (pp. 43-57). London: Pinter Pub Ltd. 
. (2005). Globalization: a critical introduction. New York: Palgrave Macmillan. 2nd ed.

SKLAIR, L. (2002), Globalization. Capitalism and its alternatives. Oxford University Press. 3rd ed. - [2003 (1995)]. Sociología del sistema global. El impacto socioeconómico y político de las corporaciones transnacionales. Barcelona: Gedisa.

Torres Torres, F. Delgadillo macías, J., Gasca Zamora, J., y Enríquez Pérez, I. (2009). Formaciones regionales comparadas. Los casos de España, Italia y México. México: UNAM, El Colegio de Tlaxcala.

WALLERSTEIN, I. [1998b (1989)]. El moderno sistema mundial. La segunda era de gran expansión de la economía-mundo capitalista, 1730-1850. México: Siglo XXI Editores.

_. [1999a (1974)]. El moderno sistema mundial. La agricultura capitalista y los orígenes de la economía-mundo europea en el siglo XVI. México: Siglo XXI Editores.

- [1999b (1980)]. El moderno sistema mundial. El mercantilismo y la consolidación de la economíamundo europea, 1600-1850. México: Siglo XXI Editores.

Waters, M. (1995). Globalization. London: Routledge/Taylor \& Francis Group. 